\title{
Ambulatory oxygen improves quality of life of COPD patients: a randomised controlled study
}

\author{
T. Eaton, J.E. Garrett, P. Young, W. Fergusson, J. Kolbe, S. Rudkin, K. Whyte
}

\begin{abstract}
Ambulatory oxygen improves quality of life of COPD patients: a randomised controlled study. T. Eaton, J.E. Garrett, P. Young, W. Fergusson, J. Kolbe, S. Rudkin, K. Whyte. (C) ERS Journals Ltd 2002.

ABSTRACT: It is unknown whether acute response to ambulatory oxygen $\left(\mathrm{O}_{2}\right)$ predicts longer term improvement in health-related quality of life (HRQL) in chronic obstructive pulmonary disease (COPD) patients.

The aims of this study were 1) to assess the short-term clinical impact, as determined by HRQL, of ambulatory $\mathrm{O}_{2}$ in a 12-week, double-blind, randomised crossover study of $\mathrm{O}_{2}$ (versus cylinder compressed air) of dyspnoeic but not chronically hypoxic COPD patients with exertional desaturation $\leqslant 88 \%(n=41)$, and 2) to determine whether either baseline characteristics or acute response to $\mathrm{O}_{2}$ predicts short-term (12 weeks) response. Primary outcome measures were Chronic Respiratory Questionnaire (CRQ), Hospital Anxiety and Depression scale and the short form (SF)-36.

Improvements were seen in all domains of the CRQ for cylinder $\mathrm{O}_{2}$ compared with cylinder air. Significant improvements were also noted in anxiety and depression and in certain domains of the SF-36. There were $28(68 \%)$ acute responders to cylinder $\mathrm{O}_{2}$ (defined as increase in 6-min walk $\geqslant 54 \mathrm{~m}$ or decrease in post-Borg dyspnoea $\geqslant 1$ ) and $23(56 \%)$ short-term responders (defined as clinically significant improvement in CRQ). However, acute and short-term responses were not correlated with no predictors of short-term response identified. At study completion, $14(41 \%)$ of acute or short-term responders did not want to continue therapy, with 11 citing poor acceptability or tolerability.

Short-term ambulatory oxygen is associated with significant improvements in healthrelated quality of life. These benefits cannot be predicted by baseline characteristics or acute response. Despite acute or short-term response, a substantial proportion of patients declined ambulatory oxygen.
\end{abstract}

Eur Respir J 2002; 20: 306-312.

Dept of Respiratory Services, Green Lane Hospital, Auckland, New Zealand.

Correspondence: T. Eaton

Respiratory Services

Green Lane Hospital, Green Lane West Auckland

New Zealand

Fax: 6496310712

E-mail: teaton@adhb.govt.nz

Keywords: Ambulatory oxygen chronic obstructive pulmonary disease exercise desaturation health-related quality of life

Received: December 42001

Accepted after revision: February 27 2002

This work was fully funded by the Health Research Council of New Zealand.
There are a considerable number of patients, not currently satisfying criteria for long-term oxygen $\left(\mathrm{O}_{2}\right)$ therapy (LTOT) [1, 2], who demonstrate significant exertional desaturation. [3, 4]. These patients may benefit from the prescription of ambulatory $\mathrm{O}_{2}$. The American Thoracic Society (ATS) guidelines for domicilary $\mathrm{O}_{2}$ state that "ambulatory $\mathrm{O}_{2}$ should be prescribed to patients normoxaemic at rest with evidence of exertional desaturation to $88 \%$ or less" [5]. More recently, the Royal College of Physicians report on Domicilary Oxygen Services stated that "ambulatory $\mathrm{O}_{2}$ should be prescribed when there is evidence of significant exercise desaturation and improvement of at least $10 \%$ in either walking distance or dyspnoea score when walking with cylinder $\mathrm{O}_{2}$ compared with cylinder air" [6].

However, guidelines for ambulatory $\mathrm{O}_{2}$ are limited and not based on randomised controlled studies. The majority of ambulatory $\mathrm{O}_{2}$ studies are acute, concentrating on physiological measures with variable results [7-12]. The longer term benefits of ambulatory $\mathrm{O}_{2}$ remain uncertain. Hence, there is a need for randomised controlled studies of the domicilary use of ambulatory $\mathrm{O}_{2}$, which incorporate not only traditional physiological measures but comprehensive health-related quality of life (HRQL) outcome measures. This should allow a more realistic assessment of the balance between practical benefits which may ensue from the use of ambulatory $\mathrm{O}_{2}$ versus the drawbacks of such an intervention. Only with such an evidence base, can guidelines be developed.

The aims of this study were 1) to assess the shortterm clinical impact, as determined by HRQL, of ambulatory $\mathrm{O}_{2}$ in patients with severe chronic obstructive pulmonary disease (COPD) and significant exercise desaturation, who did not fulfil criteria for LTOT, and 2) to determine whether either baseline characteristics or acute response predicts short-term response.

\section{Methods}

\section{Study design and patient recruitment}

Figure 1 outlines the study design and patient recruitment details. A 12-week, randomised, double-blind, 


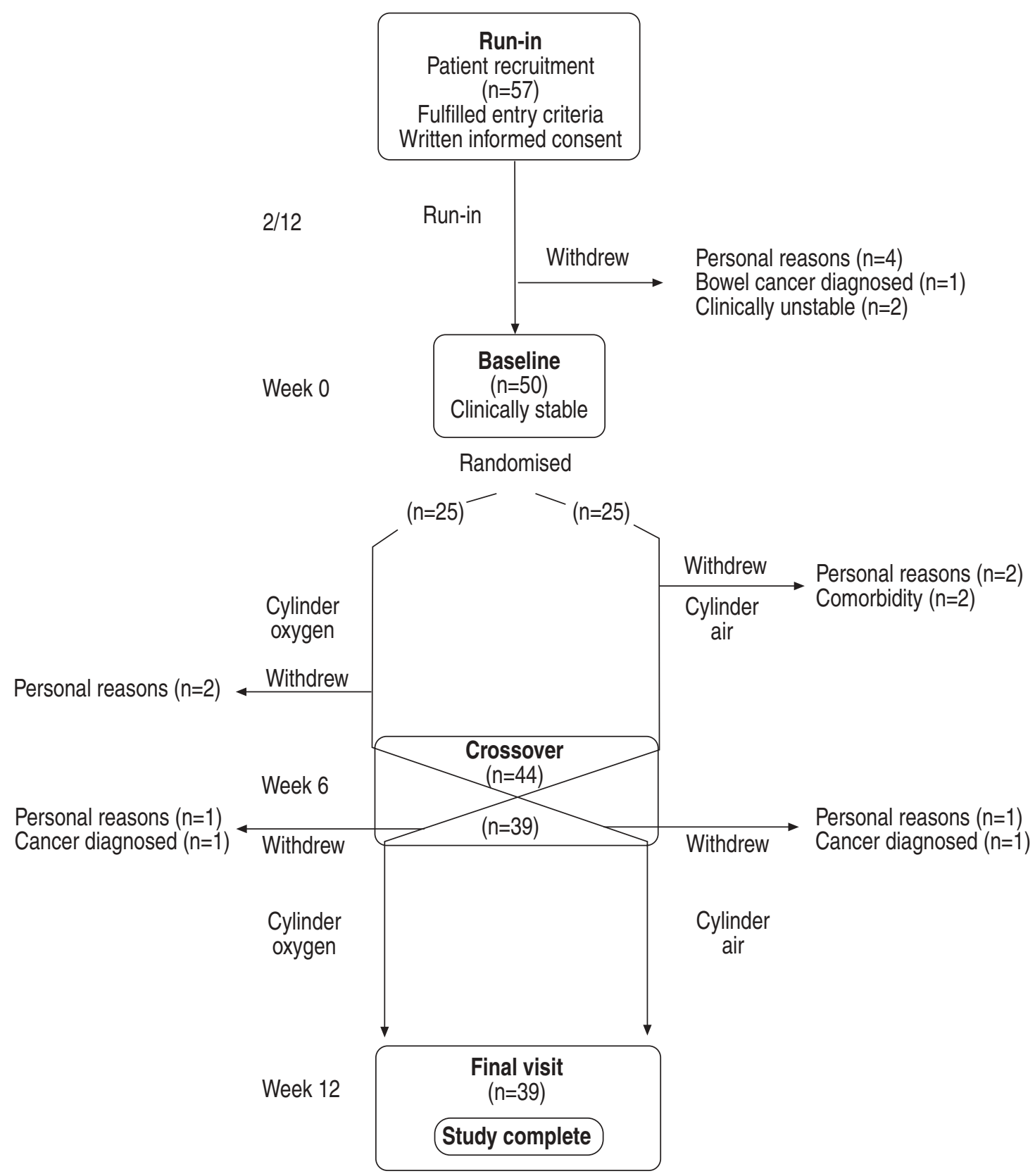

Fig. 1.-Study design and patient recruitment details.

crossover study of cylinder air and $\mathrm{O}_{2}$ was performed. Eligible patients were identified consecutively from outpatient clinics and pulmonary rehabilitation referrals to Green Lane Hospital, Auckland, NZ. Inclusion criteria were COPD as defined by ATS criteria [5], exertional dyspnoea impacting on daily activities, not fulfilling criteria for LTOT (resting oxygen tension in arterial blood $\left(\mathrm{Pa}, \mathrm{O}_{2}\right) \geqslant 7.3 \mathrm{kPa}$ on air), exertional desaturation (arterial oxygen saturation $\left(\mathrm{S}_{\mathrm{a}}, \mathrm{O}_{2}\right) \leqslant 88 \%$ on air; ATS criteria for ambulatory $\mathrm{O}_{2}$ ), exsmoker and clinically stable for over 2 months with standard optimal medical care. All patients were required to have completed a formal 6-week pulmonary rehabilitation program [13]. Patients with important comorbidities (e.g. limiting angina or significant musculoskeletal disability) were excluded. Approval was granted by the North Health Ethics Committee with signed informed consent obtained from all patients.

\section{Physiological measures}

Forced expiratory volume in one second and forced vital capacity (R-Model; Vitalograph Limited, Buckingham, UK) were performed at all visits according to ATS standards and expressed as \% of predicted using the European Coal and Steel Community prediction equations. Resting arterial blood gases on air (Quik ABG arterial blood sampler; Marquest Medical 
Products, Inc., Englewood, CO, USA) were performed at all visits other than at crossover. The 6-min walk test (6MWT) was performed in triplicate on room air prior to the baseline visit to ensure repeatability $[14,15]$. At baseline, crossover and study completion, patients performed the 6MWT carrying cylinder gas (the majority with a back pack although some patients chose a shoulder bag). Cylinder air and $\mathrm{O}_{2}$ was delivered in double-blind random order using a standard flow rate $\left(4 \mathrm{~L} \cdot \mathrm{min}^{-1}\right)$ with each test separated by 20-30 min rest. Cutaneous oximetry (Nellcor N-20PA; Puritan Bennett Inc., Pleasanton, CA, USA) was obtained with a finger probe. The following measures were recorded; resting, 2-min and 6-min $\mathrm{Sa}_{\mathrm{a}} \mathrm{O}_{2}$, walk distance, pre- and postwalk modified Borg dyspnoea scores [16]. Adequate correction of exertional desaturation was defined as $\mathrm{Sa}, \mathrm{O}_{2}>90 \%$ breathing cylinder $\mathrm{O}_{2}$

\section{Health-related quality of life measures}

Chronic respiratory questionnaire. The chronic respiratory questionnaire (CRQ) $[17,18]$ is a well-validated, repeatable and responsive disease-specific instrument with four domains; dyspnoea, fatigue, emotional function and mastery.

Hospital anxiety and depression scale. The hospital anxiety and depression scale (HAD) [19] scale is a reliable self-assessment scale for use in the physically ill, incorporating 14 items with separate scores for anxiety and depression: the subscales are also valid measures of the severity of emotional disorder.

Short form-36 health survey questionnaire. The short form (SF)-36 health survey questionnaire [20] is a generic HRQL tool with an eight-dimensional profile which has been demonstrated to be reliable and sensitive to low levels of morbidity.

\section{Domicilary programme}

Patients were randomly assigned in a doubleblinded manner to cylinder air or $\mathrm{O}_{2}$ (light weight aluminum: standard 2,000-2,200 psi fill: 145 L, weight $2.04 \mathrm{~kg}(4.5 \mathrm{lbs})$ fitted with a conserving demand gas delivery system (Oxymatic; Chad Therapeutics, Inc., Chatsworth, CA, USA). All cylinders were painted pink, prefilled with either air or $\mathrm{O}_{2}$ and identifiable only by a unique cylinder number, ensuring blinding of both participants and observers. Instructions were; to use a flow rate of $4 \mathrm{~L} \cdot \mathrm{min}^{-1}$ intranasally for any activity during which they would normally experience dyspnoea. After 6 weeks, patients crossed over to the other cylinder gas for a further 6 weeks. Patients received comprehensive practical and written education in the care and usage of their ambulatory gas. Cylinder use was quantified by weighing pre- and postuse with calibrated scales, accepted as an accurate, effective method of quantifying an amount of gas. Self-reported cylinder use was also recorded.

\section{Definitions}

The following definitions were based on published criteria for minimal clinically important differences $[14,16,18]$.

Acute response to cylinder $\mathrm{O}_{2}: 1$ ) an improvement of $\geqslant 54 \mathrm{~m}$ in the $6 \mathrm{MWT}$ on cylinder $\mathrm{O}_{2}$ compared to cylinder air or 2) a decrease in post 6MWT Borg dyspnoea score of $\geqslant 1$.

Short-term response to cylinder $\mathrm{O}_{2}$ : an improvement in dyspnoea $(\geqslant 3)$, fatigue $(\geqslant 2)$, emotional function $(\geqslant 4)$ or mastery $(\geqslant 2)$ domains of the CRQ using the validated definition of a clinically important difference.

At study completion patients were asked whether they wished to be considered for the clinical prescription of ambulatory $\mathrm{O}_{2}$. If their response was no, they were asked to state their reason(s).

\section{Statistical methods}

A mixed model approach to crossover trials was employed, which used information from all patients, including those who did not complete both time periods. Treatment and order of treatment (to exclude a carryover effect) were included in the model with the patient as a random effect. Age, baseline $\mathrm{Pa}, \mathrm{O}_{2}$ and carbon dioxide tension in arterial blood were also included as was the level of the outcome at the baseline visit. A p-value $<0.05$ was considered statistically significant. Logistic regression was used to investigate factors which might predict short-term response to cylinder $\mathrm{O}_{2}$. Included in the model were: age, sex, baseline Borg dyspnoea score pre-6MWT, difference in Borg pre- and post-6MWT on cylinder $\mathrm{O}_{2}$, difference in distance walked on cylinder $\mathrm{O}_{2}$ and cylinder air, change in $\mathrm{S}_{\mathrm{a}}, \mathrm{O}_{2}$ pre-2-min and post6MWT on air, correction of exertional desaturation, cylinder $\mathrm{O}_{2}$ use (weights) and treatment order.

\section{Results}

\section{Patient characteristics}

A total of 50 patients were available for randomisation at baseline. They had severe COPD, did not fulfil for LTOT and demonstrated significant exertional desaturation and dyspnoea (table 1). There were nine withdrawals (comorbidities $n=3$, personal reasons $\mathrm{n}=6$ ); results from the remaining 41 patients are reported. Clinical stability over the 2-month run-in period was established with no significant differences between resting $\mathrm{Pa}, \mathrm{O}_{2}$ on air, 6MWT and resting Borg dyspnoea score (run-in and baseline visit).

\section{Acute and short-term responses in functional indices}

Acute functional responses to cylinder $\mathrm{O}_{2}$ and cylinder air (6MWT and post-Borg dyspnoea scores) are shown in table 1 with significant improvement in 6MWT distance and post-6MWT Borg dyspnoea 
Table 1.-Patient characteristics including acute responses to cylinder gas

\begin{tabular}{|c|c|c|c|}
\hline & Room air & Cylinder oxygen & Cylinder air \\
\hline Subjects $n$ & 41 & & \\
\hline Age & $67.1(9.3)$ & & \\
\hline Male \% & 70 & & \\
\hline Body mass index & $23.7(4.4)$ & & \\
\hline FEV1 \% pred & $25.9(8.0)$ & & \\
\hline Resting $\mathrm{Pa}_{\mathrm{a}} \mathrm{O}_{2} \mathrm{kPa}$ & $9.2(1.0)$ & & \\
\hline Resting $\mathrm{Pa}_{\mathrm{a}} \mathrm{CO}_{2} \mathrm{kPa}$ & $5.8(0.7)$ & & \\
\hline $6 \mathrm{MWD} \mathrm{m}$ & $358(93)$ & $377^{\#}(94)$ & $337^{\#}(113)$ \\
\hline Pre-6MW $\mathrm{Sa}_{\mathrm{a}} \mathrm{O}_{2}$ & $94(1.9)$ & $96(1.7)$ & $94(1.9)$ \\
\hline Post-2MW $\mathrm{Sa}_{\mathrm{a}} \mathrm{O}_{2}$ & $87(2.9)$ & & \\
\hline Post-6MW $\mathrm{Sa}_{\mathrm{a}, \mathrm{O}_{2}}$ & $82(5.4)$ & $90(4.2)$ & $83(4.2)$ \\
\hline Pre-6MW Borg dyspnoea & $0.7(1.0)$ & $0.7(0.9)$ & $0.7(0.9)$ \\
\hline Post-6MW Borg dyspnoea & $4.7(1.6)$ & $4.1^{\oplus}(1.8)$ & $4.8(1.5)$ \\
\hline
\end{tabular}

Data are presented as mean (SD). FEV1: forced expiratory volume in one second; $P \mathrm{a}, \mathrm{O}_{2}$ : oxygen tension in arterial blood; $P$ a, $\mathrm{CO}_{2}$ : carbon dioxide tension in arterial blood; 6MWD: 6-min walk distance; $S_{\mathrm{a}}, \mathrm{O}_{2}$ : arterial oxygen saturation. ${ }^{\#}: \mathrm{p}=0.0001 ;{ }^{\natural}: \mathrm{p}=0.005$.

score observed with cylinder $\mathrm{O}_{2}$. Over the study period, there was no difference in Borg dyspnoea score post $6 \mathrm{MWT}$ on cylinder $\mathrm{O}_{2}$ depending on whether they had been assigned cylinder air or cylinder $\mathrm{O}_{2}$ in the preceding 6 weeks $(\mathrm{p}=0.4)$. Likewise, there was no difference in the distance walked on $\mathrm{O}_{2}$ depending on whether the patient had been using cylinder air or $\mathrm{O}_{2}(\mathrm{p}=0.9)$.

\section{Short-term responses in health-related quality of life}

Group analysis of mean difference between cylinder $\mathrm{O}_{2}$ and cylinder air demonstrated significant improvements in all domains of the disease-specific CRQ, both domains of the HAD and several domains of the generic $\mathrm{SF}-36$, for cylinder $\mathrm{O}_{2}$ compared with cylinder air (table 2).

\section{Cylinder gas use}

A treatment order effect was apparent in that patients who were randomised to cylinder $\mathrm{O}_{2}$ first had higher weekly use $12.25 \pm 2.06 \mathrm{~h}$ compared to cylinder air $6.95 \pm 2.12 \mathrm{~h}(\mathrm{p}=0.004)$. There was no change in the pattern of use over the weeks $(p=0.3)$.

\section{Responders to cylinder oxygen}

Using validated definitions of a minimally clinically important difference, the authors found $28(68 \%)$ acute responders to cylinder $\mathrm{O}_{2}$ and $23(56 \%)$ shortterm responders; 17 (41\%) demonstrating both acute and short-term responses (table 3). Only seven (17\%) patients were defined as neither acute nor short-term responders.

Table 2. - Health-related quality of life (HRQL) measures for 41 patients

\begin{tabular}{lccc}
\hline & Baseline & $\Delta$ cylinder oxygen-cylinder air & p-value \\
\hline Disease specific HRQL & & & \\
CRQ & & & 0.02 \\
Dyspnoea (5-35) & $16.6(5.3)$ & $2.0(0.9)$ & 0.02 \\
Fatigue (4-28) & $15.3(4.9)$ & $1.8(0.7)$ & 0.006 \\
Emotional function (7-49) & $34.3(8.0)$ & $3.3(1.2)$ & 0.008 \\
Mastery (4-28) & $19.5(4.8)$ & $1.8(0.7)$ & 0.002 \\
Total (20-140) & $85.8(18.5)$ & $8.8(2.8)$ & 0.009 \\
HAD & $5.6(4.1)$ & $-1.6(0.6)$ & 0.05 \\
Anxiety (0-21) & $4.3(2.5)$ & $-1.0(0.5)$ & \\
Depression (0-21) & & & 0.6 \\
Generic HRQL & $33.0(18.8)$ & $1.6(3.5)$ & 0.01 \\
SF-36 & $15.2(27.3)$ & $16.8(5.5)$ & 0.3 \\
Physical functioning (0-100) & $73.4(26.3)$ & $5.3(5.0)$ & $0.1(2.9)$ \\
Role physical (0-100) & $42.9(22.8)$ & $2.9(3.0)$ & 0.04 \\
Bodily pain (0-100) & $48.3(20.5)$ & $10.5(5.2)$ & 0.05 \\
General health (0-100) & $67.1(24.2)$ & $18.3(7.7)$ & 0.02 \\
Vitality (0-100) & $60.2(44.2)$ & $4.0(2.7)$ & 0.1 \\
Social functioning (0-100) & $75.6(14.7)$ & & \\
Role emotional (0-100) & & \\
Mental health (0-100) & & \\
\hline
\end{tabular}

Data are presented as mean (SD) for baseline and mean (SE) for $\Delta$ cylinder oxygen-cylinder air. CRQ: chronic respiratory questionnaire; HAD: hospital anxiety and depression; SF-36: short-form-36 health survey questionnaire. \#: higher scores indicate better HRQL; ${ }^{\uparrow}$ : higher scores indicate worse emotional function. 
Table 3.-Acute and short-term responders to cylinder oxygen

\begin{tabular}{lr}
\multicolumn{2}{c}{ Acute response } \\
Yes
\end{tabular} Notal

\begin{tabular}{lccc}
\hline Short-term response & & & \\
Yes & 17 & 6 & 23 \\
No & 11 & 7 & 18 \\
Total & 28 & 13 & 41 \\
\hline
\end{tabular}

Chi-squared test: $\mathrm{p}=0.382$.

\section{Predictors of short-term response to cylinder oxygen}

No predictors of short-term response were identified. Baseline characteristics $\left(\mathrm{Sa}, \mathrm{O}_{2}\right.$ post-6MWT, $\mathrm{Sa}, \mathrm{O}_{2}$ at $2 \mathrm{~min}$, change in $S \mathrm{a}, \mathrm{O}_{2}$ pre- and post-6MWT, Borg dyspnoea score pre- and post-6MWT) did not predict short-term response. Despite a standard prescription of relatively high flow $\left(4 \mathrm{~L} \cdot \mathrm{min}^{-1}\right)$, correction of exercise desaturation was only achieved in $26(54 \%)$ of patients and this factor also did not predict shortterm response. Quantity of $\mathrm{O}_{2}$, as measured by cylinder weights (correlation between hours of use and cylinder weights, $r=0.7$ ) did not predict short-term response. Neither was an association seen between acute response and short-term improvement in HRQL $(\mathrm{p}=0.4)$.

\section{Clinical preference for ambulatory oxygen}

At study completion, 14 (41\%) of patients, objectively defined as having either an acute or short-term response, did not want to be considered for the clinical provision of ambulatory $\mathrm{O}_{2}$, with 11 citing poor acceptability or tolerability. Of those, 20 patients that elected to continue with ambulatory $\mathrm{O}_{2}$ therapy, six $(30 \%)$ were defined as acute responders only, two $(10 \%)$ were short-term responders only and $12(60 \%)$ were both acute and short-term responders.

\section{Discussion}

The major finding of this randomised, controlled, double-blind study was improvement in HRQL with ambulatory $\mathrm{O}_{2}$ compared to cylinder air in dyspnoeic COPD subjects with exertional desaturation. This short-term benefit could not be predicted by either baseline characteristics or acute beneficial response to cylinder $\mathrm{O}_{2}$.

The current authors elected to study patients with significant exercise desaturation, consistent with current ATS recommendations for ambulatory $\mathrm{O}_{2}$ [5]. Studies of ambulatory $\mathrm{O}_{2}$ have generally been very small and concentrated on acute physiological responses [7-12]. The negative impact of COPD on HRQL is substantial [21-23], and the use of HRQL as an appropriate primary outcome measure is increasingly acknowledged. The determinants of HRQL include a complex interplay of functional disability and psychosocial variables. This study was specifically designed to examine the effect of cylinder $\mathrm{O}_{2}$ versus cylinder air on HRQL allowing a potentially powerful cylinder placebo effect to be controlled. Significant improvements between cylinder $\mathrm{O}_{2}$ and cylinder air in all domains of the disease-specific CRQ and several domains of the generic SF-36 were demonstrated.

Dyspnoea is arguably the single most distressing symptom for COPD patients. This study found small but significant improvements in the CRQ dyspnoea domain with cylinder $\mathrm{O}_{2}$ compared with cylinder air, consistent with a specific $\mathrm{O}_{2}$ effect and not supportive of alternative mechanisms, such as nonspecific stimulation of nasal receptors [24]. The mechanism of any benefit remains uncertain, but is likely to be multifactorial. There is evidence that supplemental $\mathrm{O}_{2}$ reduces minute ventilation and respiratory rate for a given workload, thus, delaying respiratory muscle fatigue [11]. Improvements in dyspnoea might relate to reduced ventilatory demand in association with reduced blood lactate [12].

However, supplemental $\mathrm{O}_{2}$ for exercise training in pulmonary rehabilitation has not to date been shown to enhance field testing outcomes [25]. Although the prescription of ambulatory $\mathrm{O}_{2}$ is not strictly analogous the current authors were also unable to demonstrate any change in functional capacity, arguing against a physiological benefit. However, this may relate to factors such as amount of use or choice of outcome measure. Each field test has strengths and weaknesses. The 6MWT was chosen in this study as it is the most widely employed field test, repeatable and responsive to change with a validated minimal clinically important difference [14]. However, the current authors acknowledge there is increasing support for endurance tests, as they are more sensitive to change [26]. Recovery time, as an outcome measure, could also be considered in future trials [27].

A specific measure of anxiety and depression in recognition of their prevalence in COPD was included in this study [21, 23]. Psychological factors may affect individual perception of dyspnoea and thus impact on HRQL. A significant decrease in anxiety and to a lesser extent depression, was demonstrated with ambulatory $\mathrm{O}_{2}$, an observation strengthened by significant improvements noted in the emotion domains of both the CRQ and SF-36. Notably emotional function and mastery were the CRQ domains where the larger impact was apparent. Mastery is defined as the degree to which a patient feels control over a disease and therefore might be expected to be a more robust and clinically relevant measure in this setting than traditional physiological indices.

The improvement in HRQL with cylinder $\mathrm{O}_{2}$, albeit significant, was modest in terms of clinical significance. Indeed, in comparison with room air the benefits may become marginal as it seems likely that there is a significant negative impact related to carrying the cylinder. However, this requires a different study design, e.g. a parallel group study incorporating a room air control arm, involving larger patient numbers. These studies are labour intensive which may explain in part the dearth of long-term clinical studies. In this study, only relatively modest 
group differences were demonstrated compared with improvements attained in some rehabilitation programs [28, 29]. However, ambulatory $\mathrm{O}_{2}$ afforded some patients measurable benefit of clinical relevance over a relatively short period of time and this effect was over and beyond any gains from an optimal therapeutic regimen including a formal period of pulmonary rehabilitation. In a disease with limited therapeutic options this is of considerable clinical importance. This study was relatively short and it remains to be determined whether any response is maintained or further incremental response accrues. Long-term studies of ambulatory $\mathrm{O}_{2}$ are warranted, incorporating additional outcome measures more critically examining activities of daily living.

Clinical responders were identified using a priori validated definitions of clinically important differences. Notably, despite acute improvement in functional indices such as walk distance or in short-term HRQL, a significant proportion elected to decline ambulatory $\mathrm{O}_{2}$. This suggests that they did not feel the clinical benefit afforded was of significant magnitude to overcome the perceived negative aspects of cylinder gas use. This occurred despite careful patient selection, absence of significant comorbidities, comprehensive patient education and individual attention to the carrier device. Intuitively, tolerability would be expected to have been captured by a measure of HRQL, this did not necessarily appear to be the case. A further point was the apparent treatment order effect. Patients randomised to cylinder air for the first 6 weeks used less cylinder $\mathrm{O}_{2}$ in the second 6-week period. Conceivably, patients who perceived no benefit with cylinder air weighted the tolerability factor higher, which then influenced their approach to the second 6-week period. The advent of smaller lighter cylinders may result in greater improvements in HRQL.

There is only one other randomised, short-term study of cylinder $\mathrm{O}_{2}$. This reported no significant difference in HRQL between cylinder air or $\mathrm{O}_{2}$ [30]. Ambulatory $\mathrm{O}_{2}$ remains widely advocated $[5,6]$ despite this negative result. The difference between the two studies may lie partly in study numbers with only 26 patients completing the study by MCDONALD et al. [30]. This study had larger numbers, employed a minimum run-in period of 2 months to ensure maximal clinical stability and to minimise potential confounders and drop-outs. All patients had completed formal pulmonary rehabilitation, another potential source of confounding. McDonald et al. [30] employed very heavy cylinders $(5 \mathrm{~kg})$ compared to the considerably lighter cylinders $(2.04 \mathrm{~kg})$ in this study. Whilst this should have been controlled for in the study design, it is possible that the negative effect of such a weight overwhelmed any small benefit from $\mathrm{O}_{2}$. It is also possible that the patient group in the study by MCDONALD et al. [30] differed in some way which made them less likely to derive benefit from ambulatory $\mathrm{O}_{2}$. The obvious difference in this respect was in degree of exercise desaturation. In this study the ATS criteria (exertional desaturation $\mathrm{Sa}_{\mathrm{a}} \mathrm{O}_{2} \leqslant 88 \%$ on air) were employed [5]. In the other study [30], exercise desaturation was not one of the selection criteria and was generally only mild. Conversely, exercise desaturation per se has not been found previously to predict acute response to cylinder $\mathrm{O}_{2}$.

No predictors of short-term response to cylinder $\mathrm{O}_{2}$ were identified. A number of baseline characteristics including dyspnoea and degree of exertional desaturation were examined; none were able to predict shortterm response. Neither was an association seen between acute response and short-term improvement in HRQL. This is not necessarily surprising, bearing in mind the acute response has been traditionally defined by improvement in functional capacity and dyspnoea whereas short-term benefit was captured by measures of HRQL, particularly mastery and emotional function. Arguably such improvements in HRQL are of greater clinical relevance to the patients. To simplify study design and maximise the proportion of patients with adequate correction of exertional desaturation a maximal tolerable flow rate of $4 \mathrm{~L} \cdot \mathrm{min}^{-1}$ was chosen here. Despite this, exertional $\mathrm{Sa}_{\mathrm{a}} \mathrm{O}_{2}$ was adequately corrected in barely one-half of the study population. As discussed, correction of $\mathrm{Sa}_{\mathrm{a}} \mathrm{O}_{2}$ was not predictive of short-term response. Previous work has generally only examined acute response but a similar lack of predictors has been reported [7-12].

In conclusion the results in this study have demonstrated that the short-term use of ambulatory oxygen is associated with significant improvements in health-related quality of life in chronic obstructive pulmonary disease patients who do not fulfil criteria for long-term oxygen therapy but who demonstrate significant exertional desaturation. How might these results influence clinical practice? Ambulatory oxygen for this group of patients appears generally acknowledged internationally, particularly in the USA, although this has not previously been evidencebased. This study provides the first evidence supporting these clinical recommendations. However, there are lingering problems. The improvements were modest, and the authors remain disadvantaged in that they are unable to predict which patients may benefit from ambulatory oxygen. Finally, poor tolerability negatively influenced decisions to proceed with ambulatory oxygen in a substantial proportion of patients. The Royal College of Physician guidelines go some way to articulating the issues, however their criteria are based on acute response [6]. The results of this study would challenge this. Formal assessment of short-term HRQL response should be mandatory. It is to be hoped that with the advent of further studies, more comprehensive evidence-based guidelines may be developed for the provision of ambulatory oxygen.

Acknowledgements. The authors would like to thank E. Robinson for assistance with statistical analyses.

\section{References}

1. Nocturnal Oxygen Therapy Trial Group. Continuous or nocturnal oxygen therapy in hypoxaemic chronic obstructive lung disease; a clinical trial. Ann Intern Med 1980; 93: 391-398. 
2. Medical Research Council Working Party. Long term domiciliary oxygen therapy in chronic hypoxic cor pulmonale complicating chronic bronchitis and emphysema. Lancet 1981; 1: 681-686.

3. Soguel Schenkel N, Burdet L, de Muralt B, Fitting JW. Oxygen saturation during daily activities in chronic obstructive airways disease. Eur Respir $J$ 1996; 9: 2584-2589.

4. Decker MJ, Arnold JL, Haney D, Masney J, Strohl KP. Extended monitoring of oxygen saturation in chronic lung disease. Chest 1992; 102: 1075-1079.

5. American Thoracic Society. Standards for the diagnosis and care of patients with chronic obstructive pulmonary disease. Am J Respir Crit Care Med 1995; 152: S77-S120.

6. Domiciliary Oxygen Therapy Services. Clinical guidelines and advice for prescribers. A report of the Royal College of Physicians of London, England, UK, 1999; $1-49$.

7. Bradley BL, Garner AE, Biliu D, Mestas JM, Forman J. Oxygen-assisted exercise in chronic obstructive lung disease. Am Rev Respir Dis 1978; 118: 239-243.

8. Woodcock AA, Gross ER, Geddes DM. Oxygen relieves breathlessness in "pink puffers". Lancet 1981; 1: 907-909.

9. Davidson AC, Leach R, George RJD, Geddes DM. Supplemental oxygen and exercise ability in chronic obstructive airways disease. Thorax 1988; 43: 965-971.

10. Dean NC, Brown JK, Himelman RB, Doherty JJ, Gold WM, Stulbarg MS. Oxygen may improve dyspnoea and endurance in patients with chronic obstructive pulmonary disease and only mild hypoxia. Am Rev Respir Dis 1992; 146: 941-945.

11. Bye PTP, Esau SA, Levy RD, et al. Ventilatory muscle function during exercise in air and oxygen in patients with chronic air-flow limitation. Am Rev Respir Dis 1985; 132: 236-240.

12. O'Donnell DE, Bain DJ, Webb KA. Factors contributing to relief of exertional breathlessness during hyperoxia in chronic airflow limitation. Am J Respir Crit Care Med 1997; 155: 530-535.

13. Young P, Dewse M, Fergusson W, Kolbe J. Improvement in outcomes for chronic obstructive pulmonary disease (COPD) attributable to a hospital-based respiratory rehabilitation programme. Aust NZ J Med 1999; 29: 59-65.

14. Redelmeier DA, Bayoumi AM, Goldstein RS, Guyatt $\mathrm{GH}$. Interpreting small differences in functional status: the six minute walk test in chronic lung disease patients. Am J Respir Crit Care 1997; 155: 1278-1282.

15. Guyatt GH, Pugsley SO, Sullivan MJ, et al. Effect of encouragement on walking test performance. Thorax 1984; 39: 818-822.

16. Wilson RC, Jones PW. Long term reproducibility of Borg scale estimates for breathlessness during exercise. Clin Sci 1991; 80: 309-312.
17. Guyatt GH, Berman LB, Townsend M, Pugsley SO, Chambers LW. A measure of quality of life for clinical trials in chronic lung disease. Thorax 1987; 42: 773778.

18. Jaeschke R, Singer J, Guyatt GH. Measurement of health status: Ascertaining the minimal clinically important difference. Control Clin Trials 1989; 10: 407-415.

19. Zigmond AS, Snaith RP. The Hospital Anxiety and Depression Scale. Acta Psychiatric Scand 1983; 67: 361-370.

20. Brazier JE, Harper R, Jones NM, et al. Validating the SF-36 health survey questionnaire: new outcome measure for primary care. BMJ 1992; 305: 160-164.

21. Curtis JR, Deyo RAHqdson LD. Health-related quality of life among patients with chronic obstructive pulmonary disease. Thorax 1994; 49: 162-170.

22. Ketelaars CAJ, Schlosser MAG, Mostert R, et al. Determinants of health-related quality of life in patients with chronic obstructive pulmonary disease. Thorax 1996; 51: 39-43.

23. Stewart AL, Greenfield RD, Hays RD, et al. Functional status and well-being of patients with chronic conditions. Results from the Medical Outcomes Study. JAMA 1989; 262: 907-913.

24. Spence DPS, Graham DR, Ahmed J, Rees K, Pearson MG, Calverley PMA. Does cold air affect exercise capacity and dyspnoea in stable chronic obstructive pulmonary disease? Chest 1993; 103: 693-696.

25. Garrod R, Paul EA, Wedzicha JA. Supplemental oxygen during pulmonary rehabilitation in patients with COPD with exercise hypoxemia. Thorax 2000; 55: 539-543.

26. Revill SM, Morgan IDL, Singh SJ, Williams J, Hardman AE. The endurance shuttle walk: a new field test for the assessment of endurance capacity in chronic obstructive pulmonary disease. Thorax 1999; 54: 213-222.

27. Calverley PMA. Supplementary oxygen therapy in COPD: is it really useful? Thorax 2000; 55: 537-538.

28. Wijkstra PJ, van Altena R, Kraan J, Otten V, Postma DS, Koeter GH. Quality of life in patients with chronic obstructive pulmonary disease improves after rehabilitation at home. Eur Respir J 1994; 7: 269-273.

29. Cambach W, Chadwick-Straver RV, Wagenaar RC, van Keimpema AR, Kemper HC. The effects of a community-based pulmonary rehabilitation programme on exercise tolerance and quality of life: a randomised controlled study. Eur Respir J 1997; 10: 104-113.

30. McDonald CF, Blyth CM, Lazarus MD, Marschner I, Barter CE. Exertional oxygen of limited benefit in patients with chronic obstructive pulmonary disease and mild hypoxemia. Am J Respir Crit Care Med 1995; 152: 1616-1619. 